\title{
Editorial: Dogmas, Stigmas, and Questionable Arguments for Better Health
}

\author{
JOHANNA AHOLA-LAUNONEN, TUIJA TAKALA, and MATTI HÄYRY
}

Everyone wants to be healthy, and everyone wants to get well when they are ill. Being healthy contributes to our ability to exercise our autonomy, and to live the lives we wish to live. According to the UNESCO Declaration of Human Rights, there are rights to health and healthcare. It would be hard to argue against the wish to be healthy-be it on an individual, social, or global level. Additionally, most theories of social justice consider health to be a primary good that should be guaranteed for every citizen. ${ }^{1,2}$

Problems start the moment we try to define "health" more precisely. Is "health" an ideal and optimal state that people should strive for but can never fully achieve? Or is "health" a state of normal functioning-an absence of disease? Broadly speaking, there are two main ways of defining health. The biomedical and reductionist view is interested in physiological anomalies, brain chemistry, viruses, bacteria and the like, and seeks to intervene with medical solutions. In this model, sickness and health are understood objectively through measurable facts. In contrast, the holistic, or social, account looks at capabilities and well-being in a wider sense, and at health more as a subjective experience. A pluralistic account of health would take both of these aspects into account. Problems arise if one side is given excessive attention over the other.

Health is also a moral concept. Being "unwell" is sometimes seen as an excuse for restricting a person's self-determination, and a reason for questioning her rationality and moral character. Throughout history, self-standing women, sexual minorities, the poor, political dissidents, and other "misfits" have experienced this, as their rights have been curtailed by appeals to sickness and related irrationality.

Protecting health, and the right to self-determination, frequently come into conflict when health is discussed. According to a widely-accepted view, society has a duty to protect individuals against health hazards. This is why most countries have safety controls on food production and food products, construction materials, cars, and pharmaceuticals, to mention but a few. However, there are limits to this. While many countries require motorcyclists to wear helmets, only some extend this to cyclists, and none do to pedestrians, although, arguably, cyclists and pedestrians would benefit from helmets as well. This is because, generally, people are assumed to have an extensive right to self-determination over their own lives and bodies. We are allowed to harm our bodies, if we want to, for example, by drinking too much, engaging in dangerous sports, overworking, and staying in abusive relationships. However, when the harm to self is seen to threaten to harm others, or when the autonomy of the person herself is brought into question, there

Acknowledgements: The authors and editors of this Special Section, Tuija Takala, Johanna AholaLaunonen, and Matti Häyry thank the Academy of Finland (project SA 307467) and the Finnish Ministry for Agriculture and Forestry (project MMM 248774) for their financial support. 
are norms and laws to safeguard third parties and nonautonomous decisionmakers. These would include, for instance, smoking bans to protect others from the harms of secondary smoke; and limited decisional power given to elders with dementia.

While few would question the value of public health measures per se, or the importance of protecting third parties from harm, the justifiable limits of these are frequently debated. What some see as justified protections against avoidable harm, others may see as unjustified instances of moralism. The notion of moralism can be understood in three different ways. First, it may mean that we see every choice as a moral one. Secondly, it may mean that we apply our good moral arguments in new and possibly unsuitable contexts. Thirdly, it may mean that we apply our own moral standards to the behavior of others. ${ }^{3,4}$

The aim of this special section is to scrutinize the various aspects of discussions on health, morality and moralism. The authors examine cases in which the moral principle of health improvement tends to override all other principles or virtues; $5,6,7$ the proper limits of harm and morality; ${ }^{8}$ and contexts in which moralityor moralism-challenge arguably-beneficial practices in public health. ${ }^{9,10}$ In this overview, the key concepts are clarified, particularly those that concern lifestylerelated chronic diseases.

\section{A Special Kind of Health}

Rising healthcare costs are regularly debated in the Western world. Reasons for this are manifold. To begin with, advances in medical sciences produce new, improved, and often expensive treatments and diagnostic tools. Furthermore, emphasis on patient choice, the contemporary response to past medical paternalism, also tends to increase healthcare costs. And these, combined with an expected decrease in tax revenues due to aging populations, have created concerns about the future of healthcare.

Lifestyle-related chronic diseases are often at the heart of these debates. Indeed, The World Health Organization (WHO) has estimated that at least a third of the disease burden in high-income countries is attributable to the use of tobacco and alcohol, high blood pressure, unhealthy cholesterol levels, and obesity. ${ }^{11}$ Insofar as the aim is to improve population health—and decrease healthcare costs—it seems fairly reasonable to focus on lifestyle-related diseases.

In the political arena, more generally, the growing trend of the "responsibilization of the individual" has shifted the focus in matters like poverty and unemployment from social structures to individual choices. ${ }^{12}$ Some say that we now live in an "age of responsibility."13 This trend is influential in health contexts, as well. It is argued that individuals should take more responsibility for their own health by adopting healthier lifestyles, and that it is unfair that in countries with national healthcare systems the responsible healthy must share the costs of the irresponsible unhealthy. Some go as far as to claim that the responsible ones should be prioritized when scarce and limited resources are distributed. Combatting chronic diseases is, obviously, a desirable goal, and there is nothing wrong with encouraging people to adopt healthy lifestyles and to take control of their lives. There are, however, more and less acceptable ways of going about this.

Looking only at the use of tobacco and alcohol, high blood pressure, unhealthy cholesterol levels, and body weight is insufficient. Other factors, such as finding 
meaning in one's life, having the ability to live according to one's own values, and having a positive self-image, all contribute to our health. ${ }^{14}$ Although a balanced diet is good for everyone, it is not necessarily the first step toward improving health, as there are many other contributing factors.

A person's lifestyle is not only up to the person herself. Her socioeconomic position and the society she lives in have an impact on the options she has. The social determinants of health have been proven to have a significant effect on health, and rather than being affected by the choices of individuals, the social determinants are, largely, shaped by policy decisions. These include education, wealth and income, food and environment, social, cultural and economic circumstances, and living conditions. Moreover, poverty, uncertainty of income, discrimination, stress, disempowerment, and inequity in genuine opportunities to participate in social and political life can all, among other things, increase the prevalence of chronic diseases and limit an individual's ability to choose. ${ }^{15}$ And all these, at least partly, have to do with how society is structured. Thus, the most efficient way to, say, improve people's diets, could be to subsidize healthy products to give them leverage against unhealthy ones, offer smaller portions, and provide healthier food in schools and workplaces rather than expecting people to change their ways voluntarily and with effort. ${ }^{16}$

New digital applications that allow people to monitor their own bodies, and the increased availability of genetic information, both further contribute to the idea that health is a personal matter. Detailed and personalized knowledge might work for some, but it hardly increases those resources that would be needed to facilitate lifestyle changes for the less resourceful. ${ }^{17,18}$

\section{Moralism of Health Responsibility}

Samuel Scheffler has identified a long-established form of political moralism, namely, the moralism of responsibility. According to Scheffler, political moralism is the use of moralistic arguments to justify policy decisions. In a similar vein, the moralism of responsibility refers to moralized concepts of individual responsibility that, for instance, place the reasons for poverty directly on the poor themselves, and in doing so, enable the well-off to feel that they can take credit for their own success without needing to be troubled by the plight of the less fortunate. ${ }^{19}$

The moralism of responsibility implies that there is something immoral about being poor, or being in need of assistance. According to this view, one should be able to manage one's life without assistance. It posits that there is something intrinsically bad in being in need of help, whereas managing one's own life is intrinsically good. The moralism of responsibility neglects the complexity of socioeconomic differences and assumes that everybody has the same possibilities to overcome the challenges they face. Policies based on moralism of responsibility are harsh, unforgiving, and insensitive to context. ${ }^{20}$

Scheffler's "moralism of responsibility" can easily be seen to apply in health matters. Moralism of health responsibility places the responsibility for health on individuals. Moreover, it enables the compliant and healthy to feel that they can take credit for their own health. The moralism of health responsibility implies that there is something immoral about not following the lifestyle guidelines.

Again, this moralism is obviously simplistic. Because of the social determinants of health, there is much more to health than individual lifestyle choices. Health 
policies that overemphasize lifestyle decisions, and place the responsibility for the harmful consequences on the individual, are unrealistic and unjust.

Why is health moralism such a prevalent phenomenon? Reasons vary, but one of them is worth a special mention. There is increasing evidence that social distances make it difficult for us to understand why people in other social groups live the way they do. This inability to understand others leads to an inability to feel empathy, and the more the behavior of "others" goes against one's own norms, the less there is understanding and empathy. These gaps in empathy result, for instance, in the unwillingness of those who are better-off to assist those who are worse-off. ${ }^{21,22}$

One of the reasons for redistributive schemes, and especially welfare-state arrangements, ${ }^{23}$ is to keep social distances at a minimum. Different schools of thought have different reasons for thinking this is important. Communitarians wish to uphold a sense of community, and their worry is that if people do not share the relevant life worlds community feeling evaporates. Rights theorists, in their turn, emphasize individuals' rights to certain social goods that can only be guaranteed by redistributive schemes, while some consequentialists argue that cooperative schemes maximize well-being in society.

It seems likely that people who use the latest digital health applications, and optimize their diets based on genetic tests, are socially quite far removed from people who struggle simply to make ends meet. Those who benefit from advanced technology fail to understand that other people's priorities, when it comes to health promotion, may lie elsewhere.

\section{Health, Harm, and Risk of Harm}

Moralistic arguments are often justified by referring to harm to others. Harm to others is, indeed, according to most moral and political theories a valid reason for restricting people's behavior. Once we start specifying what "harm" means, however, disagreements surface.

One form of health moralism is to focus on only certain detrimental factors, those that we consider "immoral," in arguing that people's ill health, brought about by their own choices, causes harm to others. This occurs, for instance, when excessive emphasis is placed on unbalanced diets, lack of exercise, overindulgent alcohol consumption and smoking, while other causes of ill health, say, dangerous sports and overwork, are ignored.

This is not to say that any argument from the viewpoint of harm to others would be completely without merit. It is true that by knowingly engaging in activities that can make us ill, we risk becoming a burden on the healthcare system. However, when one group of risky behaviors is targeted while others are overlooked, questions of moralism arise. Additionally, since lifestyle changes are difficult, and particularly difficult for those who are worse off to begin with, this argument cannot be applied indiscriminately.

A slightly different critical observation is that we can never remove all risks of harm, and even if we could, it is unlikely that we would want to. As Norman Daniels has argued, we all enjoy the benefits of people making different lifestyle choices. Tolerating risky lifestyles, occupations, and other choices, is beneficial to all, as it enables a liberal and pluralistic living space. We pose all sorts of risks to one another by our everyday decisions. By driving a car to the corner store, for 
example, instead of walking, we risk hitting a pedestrian or a child playing in the street, or injuring ourselves in an accident. Living a life comes with some risks, and this seems reasonable and justified. ${ }^{24}$ Tolerating risks and not trying to eliminate all risky choices is arguably beneficial for all, provided that the risks are fairly distributed. Daniels advocates a permissive approach to risk sharing as a means for generating the public goods of liberty and diversity. He argues that "allowing people some liberty in choosing unhealthy or risky behaviors has some redeeming social value, for it facilitates a sense of reciprocity in risk-sharing, perhaps even toleration or solidarity." 25

\section{Health Dogmatism and Murky Arguments}

Most contributors in this Special Section take issue with the fact that "health" has become an overriding moral concept in contemporary discussions. The dominant view seems to be that, if there is something we can do to improve health, we should do it. A popular addition to this is that in health considerations, the emphasis is on individuals. The thinking here is similar to many contemporary suggestions concerning genetic enhancements and their desirability. The party line in those suggestions is that if there is something that we can do to enhance human beings genetically, we should do it.

Our alleged responsibility to employ genetic engineering to make people "better" has both consequentialist and deontological defenders. Consequentialists argue that if we have the technical ability to enhance the human race, we have a responsibility and a duty to do so. ${ }^{26}$ Fairness and equity in the access to the enhancements are minor issues compared to the opportunity to reduce illness and promote people's good qualities. ${ }^{27}$ Deontological theorists maintain that we have a responsibility and a duty to make the lives of future generations longer and fuller as far as talent and achievements are concerned..$^{28}$ If a beneficial technology exists, we must use it.

This kind of whole-hearted acceptance of new technologies was criticized by Theodor Adorno and Max Horkheimer in their Dialectic of Enlightenment. ${ }^{29}$ According to Adorno and Horkheimer, the Enlightenment project that was aimed at revealing and opposing dogmatic tenets was turned on its head when the project itself began to see technological development as an end rather than as a means. Advances in technology came to be unquestioned, and what had once been a call for critical reflection and self-reflection lost its power to criticize itself, or a bastardized version of itself.

Following Adorno and Horkheimer, Andrew Edgar ${ }^{30}$ suggests that scholars who are overly enthusiastic about gene technologies have lost their ability to critically reflect on their goals. Instead of thinking about and evaluating the objectives that are worthy of pursuing, they have assumed the unquestioned truth and goodness of technological developments. Edgar's view is not necessarily hostile to new advances. Technology, including gene technology, has contributed and will contribute immensely to humanity's well-being. It is not, however, something that should be viewed uncritically, or thought of as the unquestionable and overriding moral force.

We can easily extend similar accusations of dogmatism to the discussion on health examined in this Special Section. Health, correctly interpreted, is important, and taking it as an ideal toward which we should strive is not unreasonable. 
The correct interpretation would involve health as a pluralistic and subjectively diverse notion, a capability to live a meaningful life according to one's life plan. This is not the case in current health debates, however, in which technological and scientific readings overshadow all others.

Jürgen Habermas explains this tendency by noting that since the development of science and technology are related to economic improvement, and an expansion in the range of individual choices, science has formed a strong alliance with liberalism, and this is why restrictions on science are frowned upon. ${ }^{31}$ The political ethos in liberal democracies supports liberal approaches to science. Indeed, economic considerations are closely intertwined with the promotion of health. The links are clear in the pharmaceutical industry, in healthcare services, in health media, in the nutritional industry, and in new businesses emerging around digital health products and genetic knowledge. Attempts to improve national and global health are connected to economic growth and innovation policies at a strategic level. ${ }^{32}$ This raises the question: what exactly was the original goal here?

There is nothing wrong with technology and economic benefit, and our main point is not, in general, to question their virtue or necessity. Our aim is to dispute the rationale of the moral principle of health. If we expect the principle to be strong enough to override all ethical, social, and political objections, it should have a clear meaning, or aim. This is not, however, the case. We do not know which is primary, the promotion of health or the economic gain involved. And we cannot be sure what "promotion of health" means. Is the "health" aimed at "a state of complete physical, mental and social well-being" as defined by the World Health Organization (WHO) ${ }^{33}$ Or is it a euphemism for compliance to lifestyles dictated by moralistic attitudes? Once we question what lies behind the current "principle of health" we may be in a position to reconsider our commitment to it.

\section{The Contributions}

Karoliina Snell shows us how the moral principle of health has been used as an overriding justification to legitimize data-driven medicine in Finland. The Finnish authorities argue that gathering, combining, and using health and related data is desirable and acceptable, because it is likely to lead to better health for all. What is noteworthy is the embedded double usage of autonomy and privacy in these communications. The rhetoric emphasizes privacy when the talk is about data-driven medicine, its high technical standards and strict regulations. However, any voiced concerns regarding privacy tend to get dismissed by references to the health benefits of data-driven medicine, which are taken to be more important. Similarly, with autonomy, the argument is that being able to provide people with more information and choices increases their autonomy. However, choosing not to participate, say, in the national biobanks, is met with an implicit accusation of not embracing the solidarity of contributing to the common good. Overall, the empirical analysis of the Finnish discussion reveals contradictions within the moral principle of health. Furthermore, in addition to the moral arguments, economic considerations play an important role in the endeavor to move toward data-driven medicine. This aspect is seldom explicitly discussed or balanced against the underlying ethical issues.

In his contribution, Joshua Thomas demonstrates how moralization of health occurs at the practical and conceptual levels. He shows us how "health" seems to 
possess the property of "overridingness," when levelled against other values and norms. Health is treated as a free-standing and self-justifying value, which takes precedence over any personal values a person might hold. Thomas argues that this ranking is by no means self-evident and that other personal values are not necessarily intrinsically opposed to health, and might actually support it.

Tuija Takala studies the moralistic language and arguments used in geneticsrelated practices. The arguments analyzed include the alleged duty to know one's genetic makeup, to use genetic information when making reproductive decisions, and to participate in biobank research. Her analysis shows that, in each case, at least from the Millian point of view, the duty can be questioned.

In his extensive analysis, Matti Häyry explores the conceptual background of moralism in bioethics, and how the limits of good and bad moralism have evolved in light of the harm principle within the liberal utilitarian tradition. The harm principle originated as the Millian doctrine of potential harm to others being the only legitimate argument for forcing people to act against their own will. Even though the principle still serves as a fundamental guide, it has faced several challenges and specifications through history and contexts. For example: "Should legislation look at moral principles as well, because failing to protect morality would be harmful?", "How should harm be understood-harm, hurt, offenses, or other kinds of unpleasantness to others?", "What if the individual's own will is corrupted by social pressures, emotional blackmail, and other socio-cultural influences?", and "How should potential harm be estimated without falling into exaggerated optimism or skepticism?". Häyry calls for rebooting the discussion on moralism in bioethics. By systematically looking at different approaches to justice and their applications in bioethics, he concludes that we ought to consider moralism in the light of diverse interpretations of justice.

Ainslie Heasman and Thomas Foreman discuss strategies for preventing child sexual abuse. Existing models concentrate on educating children and adults to resist, identify and report abuse; and on post-conviction practices that restrict and monitor those who have offended. It seems that we could and should do more. Heasman and Foreman consider the possibilities of preventive treatment for people with pedophilia who have not abused children. Unfortunately, stigmatization, mandatory reporting and popular opinion make it difficult to develop such programs, although a few already exist. Taking seriously the idea of harm reduction, however, a public health model to address pedophilia, augmented by mental health support and education, should be developed to help pedophiles before possible offences. While this entails a number of practical problems, this could be the best moral course of action in order to reduce harm to children.

Patrick Heavey gives an example of how following moral (or moralistic) arguments has inflicted considerable harm on people. In his extensive study of the development of the Irish healthcare system, Heavey explains the main conflicting interests that have produced a dysfunctional two-tier system that remains unable, for instance, to respond to the pre- and postnatal health needs of mothers and children. Following a more general European trend, Ireland aimed at a system of universal healthcare, but the conservative ideology of the Catholic Church was influential enough to dwarf the attempt in many areas. According to the Church, the first step toward universal healthcare-healthcare services to all expectant mothers and children before and after birth, up to 16 years-would disregard the 
importance and rights of a family unit; give too much ideological and operative power to the state in contrast to the Church; and endanger the Church's spiritual role. Heavey extends his analysis to other areas, as well, in his critical analysis of the Irish situation.

Mary Carman analyzes and evaluates different justifications for conscientious objection by medical professionals. She distinguishes three views on the matter. The first is that if a medical professional's overall reasonable moral judgement supports conscientious objection, then it is justified. The second is that if a medical professional's genuine moral intuition supports conscientious objection, then it is justified. The third states that a combination of the first two justifies conscientious objection. According to Carman the second solution only provides a psychological explanation, not a moral justification, and should be ignored. The correct solution, according to her, is the first one, calling for an overall reasonable moral judgement by the conscientiously objecting medical professional.

\section{Notes}

1. Daniels N. Just Health. Meeting Health Needs Fairly. Cambridge: Cambridge University Press; 2008.

2. Häyry M. Doctrines and dimensions of justice: Their historical backgrounds and ideological underpinnings. Cambridge Quarterly of Healthcare Ethics 2018;27:188-216.

3. Scheffler S. Choice, circumstance and the value of equality. Politics, Philosophy E Economics 2005;4(5):5-28, at 14-5.

4. Häyry M. Justice and the possibility of good moralism in bioethics. Cambridge Quarterly of Healthcare Ethics 2019;28(2):236-263.

5. Takala T. Genetic moralism and health. Cambridge Quarterly of Healthcare Ethics 2019;28(2):225-235.

6. Snell K. Health as the moral principle in post-genomic society. Data-driven arguments against privacy and autonomy. Cambridge Quarterly of Healthcare Ethics 2019;28(2):201-214. Thomas

7. Thomas SJ. Reconsidering the moralization of health: Practices versus concepts, and what we can learn from evidence based research. Cambridge Quarterly of Healthcare Ethics 2019;28(2):215-224.

8. See note 4, Häyry 2019.

9. Heasman A, Foreman T. Bioethical issues and secondary prevention for non-offending individuals with pedophilia. Cambridge Quarterly of Healthcare Ethics 2019;28(2):264-275.

10. Heavey P. The Irish healthcare system: A morality tale. Cambridge Quarterly of Healthcare Ethics 2019;28(2):276-302.

11. World Health Organization. The World Health Report: Reducing Risks, Promoting Healthy Life. Geneva: WHO; 2002.

12. The discussion here is based on Ahola-Launonen J. The evolving idea of social responsibility in bioethics: A welcome trend. Cambridge Quarterly of Healthcare Ethics 2015;24(2):204-213; AholaLaunonen J. Social responsibility and healthcare in Finland: The luck egalitarian challenge to Scandinavian welfare ideals. Cambridge Quarterly of Healthcare Ethics 2016;25(3):448-465.

13. Mounk Y. The Age of Responsibility. Luck, Choice, and the Welfare State. Cambridge, MA: Harvard University Press; 2017.

14. See note 7, Thomas 2019.

15. See e.g. note 1, Daniels 2008; Wilkinson R, Marmot M, eds. Social Determinants of Health: The Solid Facts. Copenhagen: WHO Regional Office for Europe; 1998; Mullainathan S, Shafir E. Scarcity: Why Having Too Little Means So Much. New York: Times Books; 2013

16. Mustajoki P. Obesogenic food environment explains most of the obesity epidemic [Ruokaympäristön muutos selittää pääosan västöjen lihomisesta]. Duodecim 2015;131:1345-52.

17. See note 6, Snell 2019.

18. See note 5, Takala 2019.

19. See note 3 , Scheffler 2005, at 14-15.

20. See note 3 , Scheffler 2005, at 15.

21. Saari J. The Worse-Off. [Huono-osaiset] [The Worse-Off]. Helsinki: Gaudeamus; 2015:95-7

22. Trout JD. The Empathy Gap. Building Bridges to the Good Life and the Good Society. New York: Viking; 2009. 


\section{Dogmas, Stigmas, and Questionable Arguments for Better Health}

23. Takala T. Justice for all? The Scandinavian approach. In: Rhodes R, Battin MP, Silvers A, eds. Medicine and Social Justice: Essays on the Distribution of Health Care. New York, NY: Oxford University Press; 2002:183-90.

24. Fried C. An Anatomy of Values. Cambridge, MA: Harvard University Press; 1969.

25. Daniels N. Individual and social responsibility for health. In: C. Knight C, Stemplowska Z, eds. Responsibility and Distributive Justice. Oxford University Press; 2011:266-286,278.

26. Häyry M. Rationality and the Genetic Challenge: Making People Better? Cambridge: Cambridge University Press; 2010.

27. Harris J. Enhancing Evolution: The Ethical Case for Making Better People. Princeton: Princeton University Press; 2007.

28. Ronald D. Sovereign Virtue: The Theory and Practice of Equality. Cambridge, MA: Harvard University Press; 2000:445-6,452.

29. Horkheimer M, Adorno TW. Dialectic of Enlightenment: Philosophical Fragments. Stanford, CA: Stanford University Press; 2002.

30. Edgar A. The hermeneutic challenge of genetic engineering: Habermas and the transhumanists. Medicine, Health Care, and Philosophy 2009;12(2):157-67,159-60.

31. Habermas J. The Future of Human Nature. Cambridge: Polity; 2003:24-6.

32. See note 6, Snell 2019.

33. Constitution of the World Health Organization: Principles; available at: http://www.who.int/about/ mission/en/ (last accessed 2 Sept 2018). 


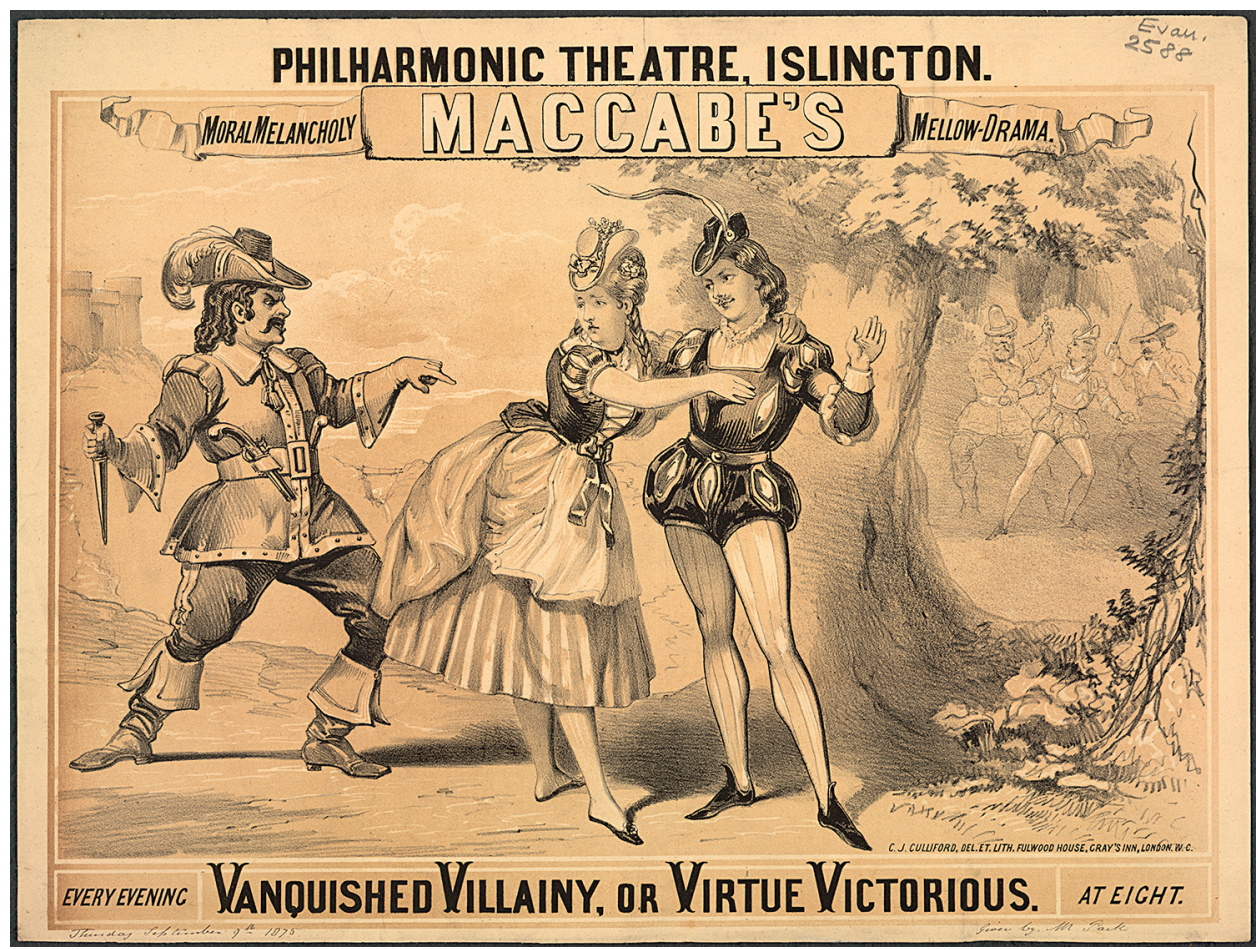

Maccabe's, A poster for a play at the Philharmonic Theatre, Islington, London. Image taken from a collection of pamphlets, handbills, and miscellaneous printed matter relating to Victorian entertainment and everyday life. Originally published/produced in London in 1875. Author: Henry Evanion. Illustrated by C J Culliford. Photo Credit: @ British Library Board / Robana / Art Resource, New York. Reproduced by Permission 